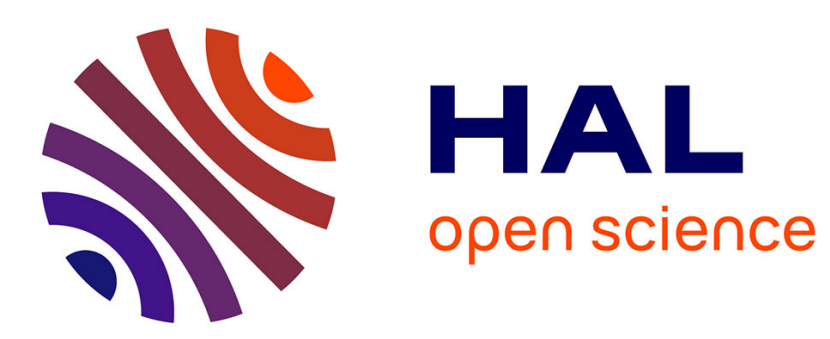

\title{
Doing better (or worse) than one's parents: Social status, mobility, and performance-avoidance goals
}

Mickaël Jury, Alisée Bruno, Céline Darnon

\section{To cite this version:}

Mickaël Jury, Alisée Bruno, Céline Darnon. Doing better (or worse) than one's parents: Social status, mobility, and performance-avoidance goals. British Journal of Educational Psychology, 2018, 88 (4), pp.659-674. 10.1111/bjep.12210 . hal-01720321

\section{HAL Id: hal-01720321 \\ https://hal.science/hal-01720321}

Submitted on 5 Oct 2021

HAL is a multi-disciplinary open access archive for the deposit and dissemination of scientific research documents, whether they are published or not. The documents may come from teaching and research institutions in France or abroad, or from public or private research centers.
L'archive ouverte pluridisciplinaire HAL, est destinée au dépôt et à la diffusion de documents scientifiques de niveau recherche, publiés ou non, émanant des établissements d'enseignement et de recherche français ou étrangers, des laboratoires publics ou privés. 
Doing Better (or Worse) than One's Parents: Social Status, Mobility and Performanceavoidance Goals.

\author{
Mickaël Jury ${ }^{1}$ \\ Alisée Bruno² \\ Céline Darnon ${ }^{2}$
}

${ }^{1}$ ESPE Lille Nord de France, PSITEC, EA 4072

${ }^{2}$ Université Clermont Auvergne

This manuscript has been accepted for publication in the British Journal of Educational Psychology on the 2017. This version is a post-print.

The authors declare that there are no potential conflicts of interest with respect to the research, authorship, and/or publication of this article.

Corresponding author: Mickaël Jury, ESPE Lille Nord de France, 365 Bis Rue Jules Guesde, 59650 Villeneuve-d'Ascq, France. Phone number: +333 207986 00. Email: mickael.jury@espe-Inf.fr. 


\begin{abstract}
Background. Previous research has shown that, when succeeding in higher education, firstgeneration (FG) students endorse more performance-avoidance goals (i.e., the fear of performing poorly) than continuing-generation (CG) students.
\end{abstract}

Aims. In this paper, individual mobility is examined as a predictor of performance-avoidance goal endorsement. It is argued that FG students endorse more these goals than CG students because in higher education, the former (but not the latter) experience upward mobility. In addition, CG can also be at risk of endorsing these goals when they are confronted with downward mobility.

Sample(s). Two studies were conducted with psychology students ( $N=143$ in Study $1 ; N=176$ in Study 2).

Methods. In Study 1, FG and CG students' perceived upward mobility was measured. In Study 2, FG and CG students were provided with a feedback that suggested either upward or downward mobility. In both studies, participants reported their level of performance-avoidance goal endorsement.

Results. Results from Study 1 supported an indirect effect of status on performance-avoidance goals via a higher perception of upward mobility. Results from Study 2 supported that psychology students who face mobility (i.e., FG students who received better feedback than their usual level of performance, CG students who received worse feedback than their usual level of performance) increased their performance-avoidance goals the most.

Conclusions. Taken together, the results of these studies support, in line with recent research, that one's actual social position and, even more, the social position one is about to reach are reliable predictors of performance-avoidance goals. 


\section{Doing Better (or Worse) than One's Parents: Social Status, Mobility, and Performance- avoidance Goals}

In the college context, first-generation (FG) students (i.e., students whose neither parent graduated from higher education) are susceptible to face far more psychological and social difficulties (e.g., lower well-being, sense of belonging, identity threat, for recent reviews see Jury et al., 2017; Stephens, Brannon, Markus, \& Nelson, 2015) than continuinggeneration (CG) students (i.e., students with at least one parent who graduated from higher education). Among other negative outcomes, FG students have been shown to be more likely than CG students to endorse performanceavoidance goals-namely, to be afraid of performing poorly (Jury, Smeding, Court, \& Darnon, 2015). The purpose of the present paper is to examine the role of the mobility process in explaining performance-avoidance goal endorsement.

\section{Status as an Antecedent of Performance- Avoidance Goal Endorsement}

According to the achievement goal theory (Elliot, 2005), in achievement contexts, individuals can pursue different kinds of goals. In particular, individuals can adopt masteryapproach goals (i.e., focused on the development of competence and/or task mastery), mastery-avoidance goals (i.e., focused on avoiding the loss of competence and/or lacking task mastery), performanceapproach goals (i.e., focused on the demonstration of superior competence), and/or performance-avoidance goals (i.e., focused on avoiding the demonstration of inferior competence; for a recent review see Senko, 2016). The latter goals are the focus of the present paper. Indeed, contrary to other types of achievement goals, research on the consequences associated with performanceavoidance goals are unambiguous: Adopting these goals is associated with several negative outcomes (Senko, Hulleman, \& Harackiewicz, 2011), including procrastination, perception of threat (McGregor \& Elliot, 2002), surface learning (Elliot \& McGregor, 2001), low feedback seeking (Payne, Young, \& Beaubien, 2007), and compliant forms of conflict regulation (Sommet et al., 2014). The adoption of performance-avoidance goals is also regularly associated with poor academic performances (for a recent meta-analysis, see Van Yperen, Blaga \& Postmes, 2014).

Research has identified several factors which may lead students to endorse these goals. Personal characteristics such as temperament (Elliot \& Thrash, 2002), personality (Chen \& Zhang, 2011) or lay theories about intelligence (Dinger \& Dickhäuser, 2013) have been identified as consistent predictors of performance-avoidance goal endorsement. In addition, some contextual incentives, such as grades, are also known to foster the endorsement of performanceavoidance goals (Pulfrey, Buchs, \& Butera, 2011). More recently, it has been argued that students' social status is also an antecedent of performance-avoidance goal endorsement (Jury, Smeding, Court et al., 2015). Indeed, FG students are more likely to endorse performance-avoidance goals than CG students, particularly at a high level of academic competence.

Why should FG students endorse more performance-avoidance goals than CG students? First, FG students are more likely than CG students to perceive their intellectual ability as low (Ivcevic \& Kaufman, 2013), to feel negative emotions (e.g., anxiety, Stephens, Townsend, Markus, \& Phillips, 2012), and/or to experience an identity threat (Jury, Smeding, \& Darnon, 2015). Interestingly, low perceived ability, negative emotions, and identity threat are precisely the three factors identified in previous research as antecedents of performance-avoidance goal endorsement (see Brodish \& Devine, 2009; Cury, Elliot, Da Fonséca, \& Moller, 2006; Pekrun, Elliot, \& Maier, 2009), which makes FG students particularly likely to endorse performanceavoidance goals. Second, research has documented that, because FG family values are less in line with university expectations than $C G$ family values, FG students experience a "mismatch" in higher education, which results in lower performance and poor emotional experiences (Stephens, Fryberg, Markus, Johnson, \& Covarrubias, 2012; see also Goudeau, Autin, \& Croizet, 2017). Such a mismatch may also increase FG students' fear 
of performing poorly. The present paper seeks to examine another reason that may explain why FG students usually endorse more performance-avoidance goals than $C G$ students: the upward mobility process that $F G$ students are experiencing in the college context (Jetten, lyer, Tsivrikos, \& Young, 2008).

\section{FG Students and the Upward Mobility Process}

Entering college opens the perspective of upward mobility for FG students. Indeed, by being the first in their family to get a chance to be a college graduate, FG students are likely to leave an unprivileged background to reach a more privileged one. Upward mobility is not a neutral process and can be particularly tough for individuals' identity (Hinz, 2016). In particular, individuals who leave their own group to access to a more privileged one face the risk of double discrimination (Branscombe \& Ellemers, 1998; Warner, Hornsey, \& Jetten, 2007) and can be rejected by both their new group, because they do not share their rules, and/or their former group for "disloyalty" (Travaglino, Abrams, Randsley de Moura, Marques, \& Pinto, 2014).

Thus, in the college context, students' identity is challenged (lyer, Jetten, Tsivrikos, Postmes, \& Haslam, 2009), particularly among FG students (Hinz, 2016). For example, Jetten et al. (2008) documented that lower social class students felt more incompatible with their new identity of university students than upper class students and that this incompatibility ended in a lower expectancy to achieve upward mobility. In the same vein, compared to CG students, FG students may feel like "outsiders" in the college context and may feel like they do not "belong" to this place (Lee \& Kramer, 2013; Rubin, 2012).

We hypothesize that this upward mobility process acts as a threat for FG students' identity-an identity threat that is likely to result in an increase in performanceavoidance goal endorsement (Brodish \& Devine, 2009; Ryan \& Ryan, 2005). In the present research, psychology students will be

\section{Table 1}

\footnotetext{
1 All material and data presented in this manuscript can be accessed at: https://osf.io/q36mf/
}

examined. Testing the role of the upward mobility process in explaining why $F G$ psychology students are more likely to endorse performance-avoidance goals than CG students is the purpose of the first study. In addition, if mobility is the key process that makes FG students endorse performanceavoidance goals, then it is reasonable to assume that CG could also be at risk of endorsing performance-avoidance goals, if they experience mobility, which, in their case, would be downward mobility (i.e., the process of losing their privileged status; see, for example, Jetten, Mols, Healy, \& Spears, 2017). Study 2 will specifically test this hypothesis ${ }^{11}$.

\section{Study 1}

In the first study, psychology students' status, perception of upward mobility, and performance-avoidance goals will be measured. In line with previous research, we expect FG students to endorse more performance-avoidance goals than $C G$ students. More importantly, we expect this effect to be due to the upward mobility experienced by FG students. Thus, an indirect effect between status and mobility on performance-avoidance goals is expected.

\section{Method}

Participants. One hundred and fortythree psychology students enrolled in a midsized French public university answered the questionnaire during a social psychology class (128 women and 15 men; $M=18.6, S D=1.02$ ).

\section{Materials and procedure.}

Status. Parental level of education was used to assess students' social status (Stephens, Fryberg et al., 2012). Participants reported their mothers' and fathers' highest degrees. Those who had at least one parent with a higher-education degree were coded as CG students $(n=71)$. The others were coded as FG students $(n=72)$. FG and CG students' characteristics in terms of gender and age are presented in Table 1.

FG and CG students' characteristics in terms of gender and age in Study 1 and Study 2. 


\begin{tabular}{lllll}
\hline & \multicolumn{2}{l}{ Study 1} & \multicolumn{2}{l}{ Study 2 } \\
\hline & FG & CG & FG & CG \\
1. Gender & & & & \\
Male & 7 & 8 & 14 & 10 \\
$\quad$ Femal & & & 96 & 56 \\
$e$ & 65 & 63 & & \\
2. Age & 18.5 & 18.6 & 20.1 & 19.9 \\
& 3 & 8 & 8 & 8 \\
\hline
\end{tabular}

Perception of mobility. A six-item scale, created for the need of the present research, measured participants' perception of mobility. Three items focused on participants' current level of education ("In your opinion, your current level of education is lower/higher than the one obtained by the most educated of your parents?"; "With your current level of education, do you feel you regress/progress compared to the level of education of the most educated of your parents?"; "Do you think your current level of education is less/more socially valued than the one obtained by the most educated of your parents?"), and three others focused on the level of education participants planned to reach ("In your opinion, will the degree you plan to obtain be lower/higher than the one obtained by the most educated of your parents?"; "With the degree you plan to obtain, do you feel you will regress/progress compared to the level of education of the most educated of your parents"; "Do you think the degree you plan to obtain will be less/more socially valued than that of the most educated of your parents?"). Participants answered on a 7-point scale (ranging from -3 to +3 ) for each item. An average score of these six items was computed to create a perception of mobility score $(\alpha=.89$, $M=1.04, S D=1.05)$. The higher the score, the more participants thought they were experiencing an upward mobility process.

Performance-avoidance goals. The three-item performance-avoidance scale was extracted from Elliot and Mc Gregor's (2001) Achievement Goal Questionnaire (validated in French by Darnon \& Butera, 2005). Questions referred to students' studies "in general." Participants indicated their degree of agreement on a 7-point scale, ranging from (1) "Not at all true for me" to (7) "Totally true for me" (e.g., "I just want to avoid doing poorly in my studies"). Responses were averaged to form a performance-avoidance goals score $(\alpha=.83, M$ $=4.78, S D=1.43$ ). Zero-order correlations among variables are presented in Table 2.

Table 2

Zero-order correlations among variables (Study 1)

\begin{tabular}{lll}
\hline Variables & 1 & 2 \\
\hline 1. Performance-avoidance & \multicolumn{2}{c}{-} \\
goals & - & \\
2. Status & $.15^{\dagger}$ & - \\
3. Upward mobility perception & $.23^{* *}$ & $.58^{\star * *}$ \\
\hline
\end{tabular}

Note. Status was scored -.5 for FG students and +.5 for CG students. ${ }^{t} p<.10,{ }^{* *} p<.01 ;{ }^{* * *} p$ $<.001$.

\section{Results}

To test the hypothesis that the perception of mobility mediated the relationship between status and performance-avoidance goal endorsement, analyses of mediation were conducted following the guidelines provided by Preacher and Hayes (2008). Status was coded -0.5 for $F G$ students and +0.5 for CG students (Davis, 2010). The perception of mobility was mean-centered. The results of this mediation analysis are displayed in Figure 1. First, status marginally predicted performance-avoidance goals, $B=-0.41, t(141)=-1.75, p=.083, \eta^{2}=$ $.02 ; 95 \%$ Cls $[-0.88,0.05]$; FG students $(M=$ 4.98; $S E=.17$ ) tended to report more performance-avoidance goals than CG students $(M=4.57 ; S E=.17)$. Second, status was significantly associated with perception of upward mobility, $B=-1.22, t(141)=-8.47, p<$ $.001, \eta^{2}=.33,95 \%$ Cls [-1.50, -0.93] (a-path); FG students $(M=0.60 ; S E=.10)$ experienced more upward mobility than $C G$ students $(M=$ $0.61 ; S E=.10)$. In addition, perception of upward mobility was positively associated with performance-avoidance goals, $B=0.31, t(141)$ $=2.76, p=.007, \eta^{2}=.05,95 \%$ Cls $[0.08,0.52]$ (b-path). Thus, the mediation analysis was tested using bootstrapping method with biascorrected confidence estimates (Preacher \& Hayes, 2004). The 95\% confidence interval of the indirect effects was obtained with 5,000 bootstrap resamples. Results of this mediation 
analysis confirmed the indirect effect of perceived upward mobility in the relationship between status and performance-avoidance goal endorsement, $B=-0.35 ; 95 \%$ Cls $[-0.72 ;-$
0.03]. In addition, the direct effect of status on performance-avoidance goals became nonsignificant when controlling for the perception of upward mobility, $B=-0.06, t(140)<1, p=.84$.

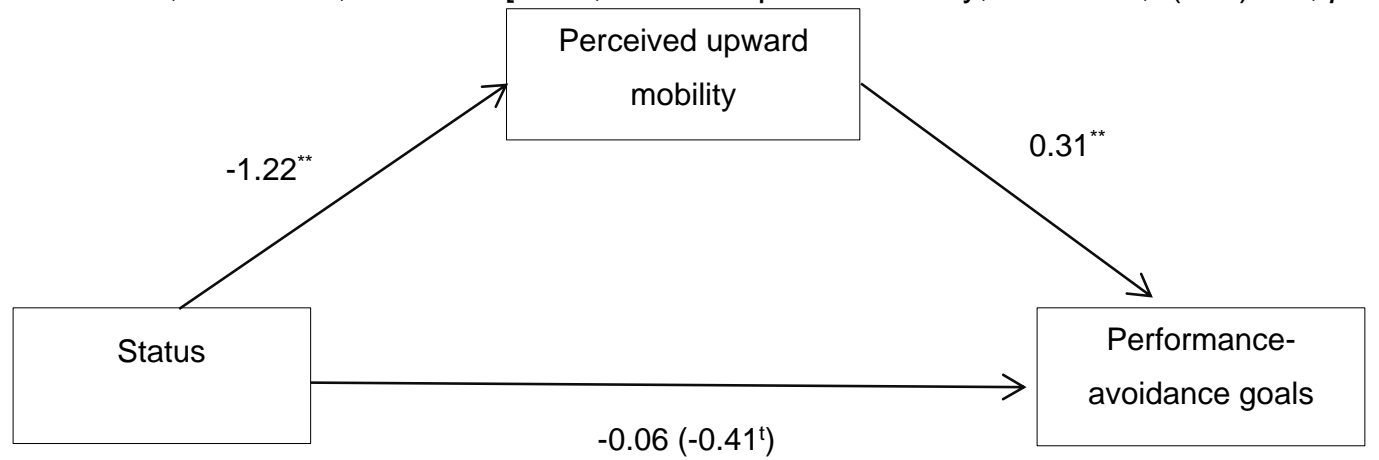

Figure 1. Indirect effect of status on performance-avoidance goals through upward mobility (Study 1 ). Note. Values indicate non-standardized regression coefficients $(B)$ with and without (in brackets) the control of perception of upward mobility. ${ }^{t} p<.10 ;{ }^{* *} p<.001$

\section{Discussion}

The results of this first study document for the first time the role of upward mobility in explaining why FG psychology students are more likely than their $C G$ counterparts to endorse performance-avoidance goals in a higher education context. As a matter of fact, FG students felt more like they were in an upward mobility process than CG students, which explains why they tended to endorse more performance-avoidance goals. This could explain why, in previous research, the $F G$ students who endorsed more performanceavoidance goals than CG students were high achievers (Jury, Smeding, Court et al., 2015). Indeed, FG high achievers are those who are the most likely to achieve the upward mobility process (i.e., they succeed at university, which means they are on target to reach a higher academic level than their parents). FG students who do not succeed are less engaged in an upward mobility process.

Thus, this study supports the idea that mobility is a key process explaining performance-avoidance goal endorsement. However, it is worth noting that most students examined in Study 1 felt they were in an upward mobility process $(87 \%$ were on the positive side of the scale). Consequently, one might wonder whether the effect is due to a mobility process per se or to the fact that this mobility process was an upward mobility process. The second study seeks to answer this question by examining the impact of both upward and downward mobility on performance-avoidance goal endorsement. Indeed, mobility is also possible for CG students. In particular, if CG students do not succeed in higher education, they are at risk of regressing on the social scale. As a matter of fact, due to the rapid expansion of educational opportunities, a number of privileged individuals risk losing their privileged background (e.g., in the U.S. context, $62 \%$ of men who start in the top quintile will fall below the top quintile; Corak, Lindquist, \& Mazumber, 2014). Thus, more and more students are facing the risk of downward mobility (Thijsen \& Wolbers, 2016). We believe that, just like individuals who experience upward mobility, individuals who experience a downward mobility process face the loss of their former affiliation and acceptance by a new social environment (Blau, 1956). Such a process is likely to result in a similar identity threat that may increase performance-avoidance goal endorsement.

Some scarce results suggest that facing the fear of failing their rank leads individuals to maladaptive behaviors. For example, Luthar, Barkin, and Crossman (2013) reported that for upper class students, "cutting back to lower paying jobs [than their parents] is not an option" (p. 1534), and that these students are exposed to several risks (e.g., drug and alcohol use; cheating). The experience of downward mobility has also been shown to be associated with a low level of subjective wellbeing (Nikolaev \& Burns, 2014) and a higher 
experience of somatic symptoms (e.g., headache, stomachache, backache, Jonsson, San Sebastian, Hammarström, \& Gustafsson, 2017).

In Study 2, both students who face an upward mobility process and students who face a downward mobility process will be examined and compared to students who do not face mobility. Individual mobility will be induced by providing $F G$ and $C G$ psychology students with fake feedback leading them to expect either success or failure at university. We hypothesize that students who experience mobility (i.e., FG who receive better feedback than usual and $C G$ students who receive worse feedback than usual) should be more likely to endorse performance-avoidance goals than students (either FG or CG) who do not face a mobility process.

A limitation of Study 1 is that performance-avoidance goals were only measured once. Thus, one cannot exclude that FG and CG students may have differed on their initial level of goal endorsement before experiencing any mobility process. In Study 2 , performance-avoidance goals will be measured twice: before and after the fake feedback. Performance-avoidance goal change will be the main dependent variable.

\section{Study 2}

\section{Method}

Participants. Psychology students (N $=195$ ) from the same university as in Study 1 voluntarily participated in this study in exchange for course credit. Nineteen were excluded from the final sample ( 6 due to missing data; 2 for incorrect answers on the experimental check; 1 outlier with a studentized residual over 5 , and 10 participants because the feedback they received did not differ from their usual level of performance ${ }^{22}$ ). The final sample included 176 participants (152 women and 24 men): 119 freshmen and 57 sophomores majoring in psychology $(M=20.10, S D=1.11)$.

Materials and procedure. Participants were seated alone in front of a computer. On the first page, the following information appeared:

2 During the process of creating these two conditions, 10 participants (2 FG and $8 \mathrm{CG}$ students) apparently received feedback that
"Several scientific studies have shown that good abilities in memorization, abstract reasoning, and logic are useful for succeeding at the university. Researchers have created a task that requires all these abilities. In the present study, you will complete this task." After these initial instructions, participants completed a first measure of performance-based goals (i.e., performance-avoidance and performanceapproach goals). Participants then read specific instructions about how to solve modular arithmetic problems (see Smeding, Darnon, \& Van Yperen, 2015). In this task, participants had to judge the validity of arithmetic problems, such as "36 $\equiv 12(\bmod 6)$." To solve the problem, participants should subtract the second number from the first (i.e., $36-12=24$ ) and divide this result by the mod (i.e., 24 / $6=4$ ). If the result is a whole number, the problem is valid and the answer is true; if not, the problem is invalid and the answer is false. Participants were asked to answer quickly and accurately. Participants were informed that they would take a 6 -item training session and, after the first 13 problems, would receive a grade based on their performance. After this training phase and before receiving this grade, participants were asked to complete a perceived competence measure. They then randomly received a grade and were asked to complete the performancebased goal scale for the second time; they finished by solving 22 new problems. At the very end, participants were asked to remember the grade they received and complete demographics measures, including their parents' level of education as well as the grade they obtained in mathematics on the French high school exit exam (i.e., baccalauréat). Finally, participants were fully debriefed.

Status. As in Study 1, participants with at least one parent with a higher-education degree were coded as CG students $(n=66)$. The others were coded as FG students $(n=$ 110). FG and CG students' characteristics in terms of gender and age can be found in Table 1.

Feedback manipulation. After the first problems, participants received fake grades

was exactly similar to their baccalauréat grade in mathematics. To avoid misattribution within one category or another, these participants were excluded from the final sample. 
(i.e., 6, 11, or $16 / 20$, based on the usual French grading system) that were allegedly based on their accuracy and reaction time. These grades, in addition to their usual level of performance in the same domain (i.e., their baccalauréat grade in mathematics, $M=12.33 / 20, S D=3.37$ ), enabled us to distinguish students who received more positive feedback than their typical level of performance from students who received more negative feedback than their typical level of performance. This resulted in four groups of interest: $F G$ students who received better feedback than usual ( $n=43)$; FG students who received worse feedback than usual $(n=67)$; CG students who received better feedback than usual ( $n=29$ ); and CG who received worse feedback than usual $(n=37)$.

\section{Performance-based}

goals.

Performance-based goals were measured twice, using the same scale as in Study 1, except that the questions referred to the experiment (e.g., "I just want to avoid doing poorly in this experiment"). Responses were averaged to form the performance-avoidance goals score at Time $1(\alpha=.78, M=3.76, S D=$ 1.55). The same items were used at Time 2 , but the instruction referred to the second part of the experiment $(\alpha=.80, M=4.07, S D=1.46)$. As the hypothesis focused on the evolution of performance-avoidance goal adoption, a change score was computed by subtracting performance-avoidance goals at Time 1 from performance-avoidance goals at Time $2(M=$ $0.32, S D=1.00$ ).

To ensure that the hypothesized effects were specific to performance-avoidance goals, participants also completed the performanceapproach goal measure at Time 1 and Time 2 (i.e., a three-item scale, "My goal is to perform better than others", $\alpha_{\mathrm{T} 1}=.92, M_{\mathrm{T} 1}=2.64, S D_{\mathrm{T} 1}$ $=1.49 ; \alpha_{\mathrm{T} 2}=.94, M_{\top 2}=2.87, S D_{\top 2}=1.52$ ) extracted from the same questionnaire (Darnon \& Butera, 2005). A change score using the same technique was computed $(M=0.23, S D=$ 0.94).

Perceived level of competence. Previous research has documented that perceived competence is a consistent predictor of performance-avoidance goals (Cury et al., 2006). Perceived competence is also associated with one's status (Ramos-Sanchez \& Nichols, 2007; Wiederkehr, Darnon, Chazal,
Guimond, \& Martinot, 2015). Thus, to ensure that the association between status and performance-avoidance goals was not only due to their common associations with perceived competence, in Study 2, this variable was measured and entered as a covariate. Participants indicated on a four-item scale (Losier, Vallerand, \& Blais, 1993) their level of agreement on a 7-point scale, ranging from 1 "totally disagree" to 7 "totally agree" (e.g., "l've developed very good abilities as a student"). Two items were reverse-coded. Answers were averaged to compute a perceived level of competence score $(\alpha=.76, M=4.35, S D=$ $0.97)$. Zero-order correlations are presented in Table 3.

\section{Results}

The regression model contained four predictors: feedback (coded -0.5 for worse feedback than usual; +0.5 for better feedback than usual), status (coded -0.5 for FG and +0.5 for CG students), and their interaction. Participants' level of perceived competence was entered as a covariate. In preliminary analyses, no effect of the independent variables was observed on this covariate; thus, the interactions between the covariate and the independent variables were not retained in the final model (Yzerbyt, Muller, \& Judd, 2004). Participants who face mobility (i.e., FG students who received better feedback than usual and CG students who received worse feedback than usual) are expected to increase their level of performance-avoidance goals, more so than the students who do not (i.e., FG students who received worse feedback than usual and $C G$ students who received better feedback than usual). Thus, we hypothesize an interaction between status and feedback on performanceavoidance goal change. 


\section{Table 3}

Zero-order correlations among variables (Study 2)

\begin{tabular}{lllllll}
\hline Variables & 1 & 2 & 3 & 4 & 5 & 6 \\
\hline
\end{tabular}

1. Performance-approach goals at Time 1

2. Performance-approach goals at Time 2

3. Performance-avoidance goals at Time $1 \quad .47^{* *} \quad . \overline{40^{* *}}$

4. Performance-avoidance goals at Time $2 \quad .38^{* *} \quad .50^{* *} \quad . \overline{78^{* *}}$

5. Perceived competence

$\begin{array}{lllll}.06 & .01 & .05 & -.06 & -\end{array}$

6. Status

$.11 \quad .16^{*} \quad-.05 \quad-.00 \quad .09$

7. Type of feedback

$\begin{array}{llllll}.04 & .07 & .08 & .07 & .03 & .05\end{array}$

Note. Status was scored -.5 for FG students and +.5 for CG students. Feedback was scored -.5 for a lower score than usual and +.5 for a better score than usual.

${ }^{*} p<.05 ;{ }^{* *} p<.01$.

Change in performance-avoidance

goal endorsement. Analyses revealed no main effect of feedback, $B=-0.13, S E=.16$, $t(171)=-0.83, p=.41, \eta_{p}^{2}=.00,95 \%$ Cls $[-$ $0.43,0.17]$, or of status, $B=0.13, S E=.16$, $t(171)=0.82, p=.42, \eta_{p}^{2}=.00,95 \%$ Cls $[-$ $0.18,0.43]$. However, the expected interaction between the two variables was significant, $B=$ $-0.62, S E=.31, t(171)=-1.99, p=.048, \eta_{p}{ }^{2}=$ $.02,95 \% \mathrm{Cls}[-1.23,-0.00]$. As illustrated in

Figure 2 and, as expected, the two conditions in which students experienced upward $(M=$ $.36 ; S E=.15)$ or downward $(M=.62 ; S E=.16)$ mobility produced a higher increase of performance-avoidance goals than the two conditions in which students did not experience mobility $(M=.18 ; S E=.12$ for $F G$ students, $M=.18$; $S E=.18$ for $C G$ students). Participants' level of perceived competence was significantly and positively related to performance-avoidance goal regulation, $B=$ $0.18, S E=.08, t(171)=-2.33, p=.021, \eta_{p}^{2}=$ $.03,95 \%$ Cls $[-0.33,-0.02] .^{3}$

Change in performance-approach goal endorsement. Analyses revealed no main effect of feedback or status, as well as no interaction between the variables (all $p s>.28$ ).

\section{Discussion}

As expected, the experience of mobility (either upward or downward) resulted in an increase in students' performanceavoidance goal endorsement. Indeed, FG students who faced the possibility of upward mobility as well as CG students who faced the possibility of downward mobility increased their endorsement of performance-avoidance goals more than $F G$ and $C G$ students who did not face mobility. This effect appeared when students' level of perceived competence was controlled, evacuating an explanation of the differences between students who face mobility (either upward or downward) and those who do not purely in terms of perceived competence. Even if the effect size is quite low, the present findings, in line with Study 1 and previous research, bring another piece of evidence to the idea that one's social position (either actual or future) influences one's performance-avoidance goal endorsement.
${ }^{3}$ It is worth noting that, as gender can be linked to performance-avoidance goal endorsement (Dekker et al., 2013), additional analyses including gender as a covariate were conducted. The results were unchanged. 


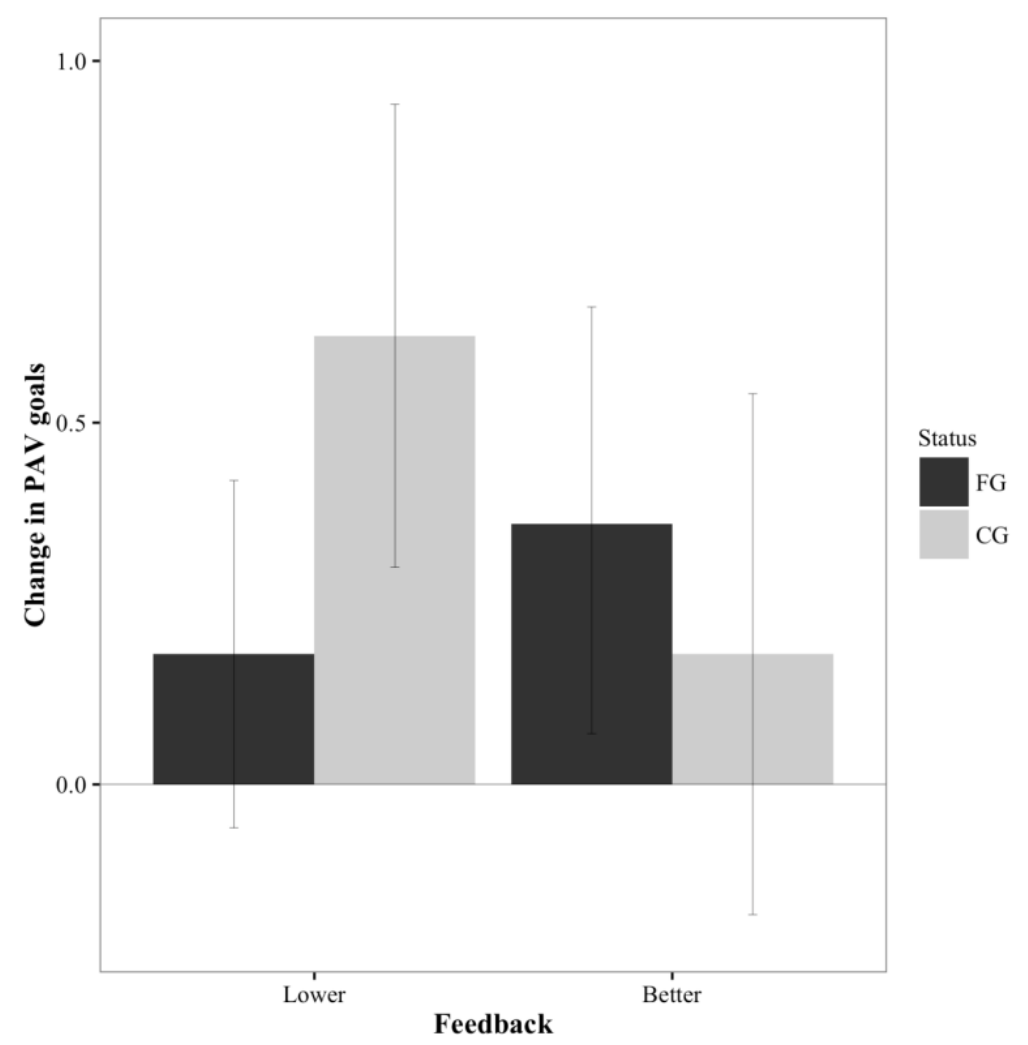

Figure 2. Change in performance-avoidance (PAV) goal endorsement depending on feedback and status. Errors bars represent $95 \%$ Cls.

\section{General Discussion}

As developed herein, FG students who succeed in higher education are more likely to endorse performance-avoidance goals than their CG students' counterparts (Jury, Smeding, Court et al., 2015). In the present paper, we argued that this may be partially due to the upward mobility process that FG students are experiencing when succeeding in college. Indeed, by being the first of their family to pursue higher education, FG students have reasonable chances to achieve a higher level of education than their parents, subsequently find a better job and, in fine, live in a more privileged social group. Such a process is particularly challenging for individuals' identity (Lee \& Kramer, 2013; Jetten et al., 2008; Stephens, Fryberg et al., 2012). Thus, in line with previous research, we argued that experiencing upward mobility could be particularly threatening for FG students' identity-a threat that could lead them to increase their endorsement of performanceavoidance goals (Ryan \& Ryan, 2005). The results of the first study confirmed that the higher endorsement of performance-avoidance goals by FG psychology students (compared to CG students) is mediated by their perception of upward mobility. In other words, in the college context, FG students experience upward mobility, which leads them to endorse more performance-avoidance goals than their CG counterparts. In Study 2, we argued that CG may also be at risk of endorsing performanceavoidance goals. In particular, CG students who fail in higher education are at risk of experiencing downward mobility because they may reach a lower academic level than their parents. It was argued that, if the key mechanism explaining higher endorsement of performance-avoidance goals was mobility, then both FG and CG could increase their level of performance-avoidance goal endorsement: the former, in case of success (i.e., upward mobility), and the latter, in case of failure (downward mobility). In other words, we hypothesized that more than students' status per se, mobility (either upward or downward) is a key determinant of performance-avoidance goal endorsement. The results obtained in Study 2 confirmed that FG psychology students who performed better than usual (i.e., students who experienced upward mobility) as well as CG psychology students who performed poorer than usual (i.e., students who experienced downward mobility) both increased their 
endorsement of performance-avoidance goals, unlike FG and CG psychology students who did not face mobility.

Taken together, the results of these two studies contribute to document, in line with recent research, that in psychology universities, one's actual social position and, even more, the social position one is about to reach are important predictors of achievement goal endorsement (Berger \& Archer, 2015; Darnon, Dompnier, \& Poortvliet, 2012). Interestingly, in an early hierarchical model of achievement motivation, Elliot (1999) already indicated that: "Research on various forms of avoidance motivation (...) suggests that women, ethnic minorities, and individuals from lower socioeconomic backgrounds and interdependent cultures may be most susceptible to performance-avoidance regulation" (p. 175). However, this idea has only received moderate support (for examples, see Berger \& Archer, 2016; Sommet, Quiamzade, Jury, \& Mugny, 2015). We believe the present findings importantly clarify this issue. Notably, the results show that, more than social status per se, what seems to be fundamental is the extent to which students experience, or not, mobility. Because FG students by default face an upward mobility process when succeeding in higher education, these students are likely to endorse performance-avoidance goals (Jury, Smeding, \& Darnon, 2015; Jury, Smeding, Court et al., 2015). In this previous research, the effect of status was mostly observed at a high academic achievement level, supporting the idea that FG who experience the most upward mobility are those who endorse performanceavoidance goals. The present research complements these findings by showing that CG students may also endorse such goals if they experience downward mobility.

These two studies are not without limitations. First, the two studies focused on psychology students. Although typical in goal research, this means that the findings cannot be generalized to other student populations. In particular, in psychology universities, gender is not well-balanced. In the present samples, for example, women represented more than $85 \%$. As women are more likely to be FG students (Engle \& Tinto, 2008) and to endorse performance-avoidance goals (Dekker et al., 2013) than men, this gender composition could partially explain the present findings. In addition, in a more gender-balanced, or maledominated fields of studies, gender may interact with status in predicting performanceavoidance goals. For example, in a maledominated field of study (e.g., engineering), and contrary to female-dominated fields of studies (e.g., psychology), female FG students may be exposed to double discrimination and thus, may be particularly likely to endorse performanceavoidance goals, more so than male participants. For these reasons, replicating the present findings in different fields of study, either gender-balanced, or male-dominated, would represent an important added value to the present study. In addition, contrary to what is usually observed in the literature (e.g., Stephens, Fryberg, et al., 2012), in the present studies, FG students were either equally or more represented than CG students, which is typical of French psychology universities. We argue that the upward mobility process could be even more difficult for FG students in contexts with lower social mixing-namely, with a higher proportion of CG students. For this reason, more elitist fields of studies (e.g., medical studies), where the vast majority of students are CG students, should be examined in future research. In addition, the studies are both correlational and cross-sectional. Students' status is an invoked variable, the manipulation of students' mobility in the second study implied a comparison with students' past level of performance, and all measures were taken at the same time. Consequently, no clear causal conclusions can be drawn.

Despite these limitations, we believe the present findings open interesting perspectives for research and practice. As developed herein, a large consensus exists among authors on the fact that performanceavoidance goals are deleterious forms of motivation that are recurrently associated with negative outcomes (Senko et al., 2011; Van Yperen et al., 2014). As a result, students who experience mobility are particularly at risk in higher education. Indeed, the high endorsement of maladaptive goals may reinforce their difficulties, resulting in an important vicious circle for these students. Because of their academic success, FG students who achieve quite well in higher education are certainly not considered to be the most "at risk" by teachers 
and educational policies, precisely because they succeed. However, the present findings indicate that, despite their success, these students may face far more difficulties than those who do not face mobility challenges. For that reason, we believe this population deserves particular attention and should probably be the most targeted by educational interventions. For example, the intervention proposed by Stephens, Hamedani, and Destin (2014) could be highly recommended because, in it, highly competent FG students learn tools and strategies to overcome the difficulties associated with their backgrounds and succeed as well as CG students.

\section{References}

Berger, N., \& Archer, J. (2015). The relationship between social class and students' academic achievement goals. In C. M. Rubie-Davies, J. M. Stephens, \& P. Watson (Eds.), Routledge International Handbook Of Social Psychology Of the Classroom (pp. 31-41). New York: Routledge. doi: 10.4324/9781315716923.ch3

Berger, N., \& Archer, J. (2016). School socioeconomic status and student socioacademic achievement goals in upper secondary contexts. Social Psychology of Education, 19(1), 175-194. doi: 10.1007/s11218-015-9324-8.

Blau, P. M. (1956). Social Mobility and Interpersonal Relations. American Sociological Review, 21(3), 290-295.

Branscombe, N. R., \& Ellemers, N. (1998). Coping with group-based discrimination: individualistic versus group-level strategies. In J. K. Swim \& C. Stangor (Eds.), Prejudice: The target's perspective (pp. 243-266). NewYork: Academic Press.

Brodish, A. B., \& Devine, P. G. (2009). The role of performance-avoidance goals and worry inmediating the relationship between stereotype threat and performance. Journal of Experimental Social Psychology, 45(1), 180-185. doi:10.1016/ j.jesp.2008.08.005.
Chen, C., \& Zhang, L. (2011). Temperament, personality and achievement goals among Chinese adolescent students. Educational Psychology, 31(3), 339-359. doi: 10.1080/01443410.2011.559310

Corak, M., Lindquist, M. J., \& Mazumder, B. (2014). A comparison of upward and downward intergenerational mobility in Canada, Sweden and the United States. Labour Economics, 30, 185-200. doi: 10.1016/j.labeco.2014.03.013

Cury, F., Elliot, A. J., Da Fonseca, D., \& Moller, A. C. (2006). The social-cognitive model of achievement motivation and the $2 \times 2$ achievement goal framework. Journal of Personality and Social Psychology, 90(4), 666-679. doi: 10.1037/00223514.90.4.666

Darnon, C., \& Butera, F. (2005). Buts d'accomplissement, stratégies d'étude, et motivation intrinsèque: Présentation d'un domaine de recherche et validation française de l' échelle d'Elliot et McGregor (2001) [Achievement goals, study strategies, and intrinsic motivation: Presenting a domain of research and the French validation of Elliot and McGregor's (2001) scale]. L'Année Psychologique, 105, 105-131 doi:10.3406/psy.2005.3821

Darnon, C., Dompnier, B., \& Poortvliet, M. (2012). Achievement goals in educational contexts: A social psychology perspective. Social and Personality Psychology Compass, 6(10), 760-771. doi:10.1111/j.1751-9004.2012.00457.x

Davis, M. J. (2010). Contrast coding in multiple regression analysis: Strengths, weaknesses, and utility of popular coding structures. Journal of Data Science, 8(1), 61-73.

Dekker, S., Krabbendam, L., Lee, N. C., Boschloo, A., de Groot, R., \& Jolles, J. (2013). Sex differences in goal orientation in adolescents aged 10-19: The older boys adopt work-avoidant goals twice as often as girls. Learning and Individual Differences, 26, 196-200. doi: 10.1016/j.lindif.2012.07.011 
Dinger, F. C., \& Dickhäuser, O. (2013). Does implicit theory of intelligence cause achievement goals? Evidence from an experimental study. International Journal of Educational Research, 61, 38-47. doi: 10.1016/j.ijer.2013.03.008

Elliot, A. J. (1999). Approach and avoidance motivation and achievement goals. Educational Psychologist, 34, 169-189. doi: $10.1207 / \mathrm{s} 15326985 \mathrm{ep} 3403$

Elliot, A. J. (2005). A conceptual history of the achievement goal construct. In A. Elliot and C. Dweck (Eds.), Handbook of Competence and Motivation (pp. 52-72). New York, NY: Guilford Press.

Elliot, A. J., \& McGregor, H. A. (2001). A 2× 2 achievement goal framework. Journal of Personality and Social Psychology, 80(3), 501-519. doi: 10.1037/00223514.80.3.501

Elliot, A. J., \& Thrash, T. M. (2002). Approachavoidance motivation in personality: Approach and avoidance temperaments and goals. Journal of Personality and Social Psychology, 82(5), 804-818. doi: 10.1037/0022-3514.82.5.804

Engle, J., \& Tinto, V. (2008). Moving beyond access: College success for low-income, first-generation students. Washington, DC: Pell Institute for the Study of Opportunity in Higher Education (ERIC Document Reproduction Service No. ED504448)

Goudeau, S., Autin, F. \& Croizet, J.-C., (2017). Etudier, Mesurer et Manipuler la Classe Sociale en Psychologie Sociale: Approches Economiques, Symboliques et Culturelles [Studying, Measuring and Manipulating Social Class in Social Psychology: Economic, Symbolic and Cultural Approaches]. International Review of Social Psychology, 30(1), 1-19. doi: 10.5334/irsp.52

Hinz, S. E. (2016). Upwardly Mobile: Attitudes Toward the Class Transition Among FirstGeneration College Students. Journal of College Student Development, 22(3), 285-299. doi: 10.1353/csd.2016.0033
Ivcevic, Z., \& Kaufman, J. C. (2013). The can and cannot do attitude: How selfestimates of ability vary across ethnic and socioeconomic groups. Learning and Individual Differences, 27, 144-148. doi:10.1016/j.lindif.2013.07.011

lyer, A., Jetten, J., Tsivrikos, D., Postmes, T., \& Haslam, S. A. (2009). The more (and the more compatible) the merrier: multiple group memberships and identity compatibility as predictors of adjustment after life transitions. British Journal of Social Psychology, 48(4), 707-733. doi: 10.1348/014466608X397628

Jetten, J., lyer, A., Tsivrikos, D., \& Young, B. M. (2008). When is individual mobility costly? The role of economic and social identity factors. European Journal of Social Psychology, 38(5), 866-879. doi:10.1002/ejsp.471

Jetten, J., Mols, F., Healy, N., \& Spears, R. (2017). "Fear of Falling": Economic Instability Enhances Collective Angst among Societies' Wealthy Class. Journal of Social Issues, 73(1), 61-79. doi: 10.1111/josi.12204

Jonsson, F., Sebastian, M. S., Hammarström, A., \& Gustafsson, P. E. (2017). Intragenerational social mobility and functional somatic symptoms in a northern Swedish context: analyses of diagonal reference models. International Journal for Equity in Health, 16(1), 1. doi:10.1186/s12939-016-0499-1

Jury, M., Smeding, A., Stephens, N. M., Nelson, J. E., Aelenei, C., \& Darnon, C. (2017). The Experience of Low-SES Students in Higher Education : Psychological Barriers to Success and Interventions to Reduce Social-Class Inequality. Journal of Social Issues, 73(1), 23-41. doi: 10.1111/josi.12202

Jury, M., Smeding, A., Court, M., \& Darnon, C. (2015). When first-generation students succeed at university: On the link between social class, academic performance, and performance-avoidance goals. Contemporary Educational Psychology, 41, 25-36. doi: 10.1016/j.cedpsych.2014.11.001 
Jury, M., Smeding, A., \& Darnon, C. (2015). First-generation students' underperformance at university: the impact of the function of selection. Frontiers in Psychology, 6, 710. doi: 10.3389/fpsyg.2015.00710

Lee, E. M., \& Kramer, R. (2013). Out with the old, in with the new? Habitus and social mobility at selective colleges. Sociology of Education, 86(1), 18-35. doi: $10.1177 / 0038040712445519$

Losier, G. F., Vallerand, R. J., \& Blais, M. R. (1993). Construction et validation de l'Échelle des Perceptions de Compétence dans les Domaines de Vie (EPCDV). [Construction and validation of the Perceived Competence in Life Domains Scale (PCLDS).] Science et Comportement, 23(1), 1-16.

Luthar, S. S., Barkin, S. H., \& Crossman, E. J. (2013). "I can, therefore I must": Fragility in the upper-middle classes. Development and Psychopathology, 25, 1529-49. doi: 10.1017/S0954579413000758

McGregor, H. A., \& Elliot, A. J. (2002). Achievement goals as predictors of achievement-relevant processes prior to task engagement. Journal of Educational Psychology, 94(2), 381-395. doi: 10.1037/0022-0663.94.2.381

Nikolaev, B., \& Burns, A. (2014). Intergenerational mobility and subjective well-being-Evidence from the general social survey. Journal of Behavioral and Experimental Economics, 53, 82-96. doi: 10.1016/j.socec.2014.08.005

Payne, S. C., Youngcourt, S. S., \& Beaubien, J. M. (2007). A meta-analytic examination of the goal orientation nomological net. Journal of Applied Psychology, 92(1), 128-150. doi: 10.1037/00219010.92.1.128

Pekrun, R., Elliot, A. J., \& Maier, M. A. (2009). Achievement goals and achievement emotions: Testing a model of their joint relations with academic performance. Journal of Educational Psychology, 101(1), 115-135. doi: 10.1037/a0013383
Preacher, K. J., \& Hayes, A. F. (2004). SPSS and SAS procedures for estimating indirect effects in simple mediation models. Behavior Research Methods, Instruments, \& Computers, 36(4), 717731. doi: 10.3758/BF03206553

Preacher, K. J., \& Hayes, A. F. (2008). Asymptotic and resampling strategies for assessing and comparing indirect effects in multiple mediator models. Behavior Research Methods, 40(3), 879-891. doi: 10.3758/BRM.40.3.879

Pulfrey, C., Buchs, C., \& Butera, F. (2011). Why grades engender performance avoidance goals: the mediating role of autonomous motivation. Journal of Educational Psychology, 103(3), 683700. doi: 10.1037/a0023911

Ramos-Sánchez, L., \& Nichols, L. (2007). Selfefficacy of first-generation and non-firstgeneration college students: The relationship with academic performance and college adjustment. Journal of College Counseling, 10, 6-18. doi:10.1002/j.2161-1882.2007.tb00002.x

Rubin, M. (2012). Social class differences in social integration among students in higher education: A meta-analysis and recommendations for future research. Journal of Diversity in Higher Education, 5(1), 22-38. doi:10.1037/a0026162

Ryan, K. E., \& Ryan, A. M. (2005). Psychological processes underlying stereotype threat and standardized math test performance. Educational Psychologist, 40(1), 53-63. doi:10.1207/s15326985ep4001_4

Senko, C. (2016). Achievement goal theory: A story of early promises, eventual discords, and future possibilities. In $\mathrm{K}$. Wentzel \& D. Miele (Eds), Handbook of Motivation at School, Vol. 2 (pp. 75-95). New York, NY: Taylor \& Francis.

Senko, C., Hulleman, C. S., \& Harackiewicz, J. M. (2011). Achievement goal theory at the crossroads: Old controversies, current challenges, and new directions. Educational Psychologist, 46(1), 26-47. doi: 10.1080/00461520.2011.538646 
Smeding, A., Darnon, C., \& Van Yperen, N. W. (2015). Why do high working memory individuals choke? An examination of choking under pressure effects in math from a self-improvement perspective. Learning and Individual Differences, 37, 176-182. doi: 10.1016/j.lindif.2014.11.005

Sommet, N., Darnon, C., Mugny, G., Quiamzade, A., Pulfrey, C., Dompnier, B., \& Butera, F. (2014). Performance goals in conflictual social interactions: Towards the distinction between two modes of relational conflict regulation. British Journal of Social Psychology, 53(1), 134153. doi: $10.1111 /$ bjso. 12015

Sommet, N., Quiamzade, A., Jury, M., \& Mugny, G. (2015). The student-institution fit at university: Interactive effects of academic competition and social class on achievement goals. Frontiers in

Psychology, 6, 1-11. doi: 10.3389/fpsyg.2015.00769

Stephens, N. M., Brannon, T. N., Markus, H. R., \& Nelson, J. E. (2015). Feeling at home in college: Fortifying school-relevant selves to reduce social class disparities in higher education. Social Issues and Policy Review, 9(1), 1-24. doi: 10.1111/sipr.12008

Stephens, N. M., Fryberg, S. A., Markus, H. R., Johnson, C. S., \& Covarrubias, R. (2012). Unseen disadvantage: How American universities' focus on independence undermines the academic performance of first-generation college students. Journal of Personality and Social Psychology, 102(6), 1178-1197. doi:10.1037/a0027143

Stephens, N. M., Hamedani, M. G., \& Destin, M. (2014). Closing the social-class achievement gap: a difference-education intervention improves first-generation students' academic performance and all students' college transition. Psychological Science, 25(4), 943-953. doi:10.1177/0956797613518349
Stephens, N. M., Townsend, S. S. M., Markus, H. R., \& Phillips, L. T. (2012). A cultural mismatch: Independent cultural norms produce greater increases in cortisol and more negative emotions among firstgeneration college students. Journal of Experimental Social Psychology, 48(6), 1389-1393. doi: 10.1016/j.jesp.2012.07.008

Thijssen, L., \& Wolbers, M. H. J. (2016). Determinants of Intergenerational Downward Mobility in the Netherlands. Social Indicators Research, 128(3), 9951010. doi: 10.1007/s11205-015-1066-7

Travaglino, G. A., Abrams, D., Randsley de Moura, G., Marques, J. M., \& Pinto, I. R. (2014). How groups react to disloyalty in the context of intergroup competition: Evaluations of group deserters and defectors. Journal of Experimental Social Psychology, 54, 178-187. doi: 10.1016/j.jesp.2014.05.006

Van Yperen, N. W., Blaga, M., \& Postmes, T. (2014). A meta-analysis of self-reported achievement goals and nonself-report performance across three achievement domains (work, sports, and education). PLOS ONE, 9(4). doi: 10.1371/journal.pone.0093594

Warner, R., Hornsey, M. J., \& Jetten, J. (2007). Why Minority Group Members Resent Impostors. European Journal of Social Psychology, 37(1), 1-17. doi:10.1002/ejsp.332

Wiederkehr, V., Darnon, C., Chazal, S., Guimond, S., \& Martinot, D. (2015). From social class to self-efficacy: internalization of low social status pupils' school performance. Social Psychology of Education, 18(4), 769-784. doi: $10.1007 / \mathrm{s} 11218-015-9308-8$

Yzerbyt, V. Y., Muller, D., \& Judd, C. M. (2004). Adjusting researchers' approach to adjustment: On the use of covariates when testing interactions. Journal of Experimental Social Psychology, 40(3), 424-431. doi: 10.1016/j.jesp.2003.10.001 